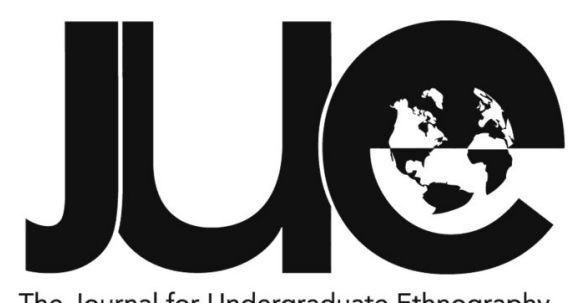

The Journal for Undergraduate Ethnography

\title{
The Affect of the State: Affective Responses to the Bureaucratic State Structures of Migration to Chile
} Maria Schrupp

College of Saint Benedict, mcschrupp23@gmail.com

\section{ABSTRACT}

As human resettlement becomes increasingly frequent, it is crucial to gain a deep understanding of the affective realities of migrants. This article uses qualitative methods such as participant observation and semi-structured interviews to explore the emotions and feelings Venezuelan migrants experience during their relocation to Santiago, Chile. Fieldwork for this project took place between June and August of 2019. During this time, Chile experienced an exponential increase in migrants due to the Venezuelan crisis and a resulting rise in social tensions. This article focuses on Venezuelan migrants' dual affective responses to the state and the bureaucratic processes they encounter as they begin to experience everyday life in Chile. Specifically, I explore narratives concerning the negative emotions experienced by Venezuelan migrants when negotiating with bureaucratic structures, and the positive emotions toward the abstract state that created and ran those structures.

Keywords: migration; bureaucracy; Venezuela; Chile 
L ucia, a middle-aged, Venezuelan migrant, was standing at the front of her classroom on the first day of class. She had been a professor for her entire adult life and year after year, she stood in that very spot and looked out at the seats in front of her to see the eager eyes of students looking back. She recalled fondly the days when students would chatter as their new books and notebooks were placed neatly in front of them. But the past year was different, she said. There were no books, no chatter, and, a once filled classroom, now had only four students in it. This was the image that Lucia described to me with difficulty as she reminisced about her home country which she had been forced to leave a short two weeks earlier. She simply could not exist in Venezuela anymore. What she knew how to do was teach, but students could not afford books anymore, in fact, they could not even afford photocopies of books. The few students who were still enrolled frequently missed class because venturing to campus meant putting themselves in danger and they could not work remotely as the internet and phone signals would disappear for days at a time. With no indication that the situation would improve, Lucia felt that she had to leave her country. Choking up as she explained the difficulty of deciding to leave her home, her culture, and her family, she made it clear that she would not have left if she felt she had the option to stay.

Lucia's story is far from unique. The United Nations Department on Economic and Social Affairs estimates that the number of international migrants worldwide was nearly 272 million in 2019 - just under 3\% of the total global population (United Nations 2019). As Lucia's story shows, migration is an emotional experience. Making the decision to leave one's home, one's culture, one's family, and everything familiar is, at its core, emotionally difficult. Relocation and adapting to a new place and society is equally emotionally taxing. Therefore, in order to fully understand migration, it is imperative to study the affect it produces and the implications that emotions have on an individual's choices, understandings of one's relationship to state entities, and the everyday reality of negotiating life as a migrant.

For a wide range of reasons, many people make the hard decision to relocate. Immigrants to a new country must navigate interactions with large structures that are simultaneously abstract and unknown to them, yet deeply intertwined in their daily lives. Migrants' affective responses to the macro and micro level structures involved in the immigration process in Santiago, Chile provide important insight into the reality of migration and the nuances of relationships to the state. These structures often produce immediate frustration for migrants in return for needed security and comfort. These contrasting emotions are constantly in contention for migrants as they settle into their new positions in Chile and begin to grapple with new government entities.

\section{The Chilean Migratory Context}

It was not until the return to a democratic state in the late 1990's that Chile experienced a significant level of immigration. Since this time, immigration rates have continued to increase, although the origins of immigrants have changed over time with "growing numbers of Peruvians and Bolivians starting in the 1990s, and Haitians, Colombians, and Venezuelans in the 2000s and 2010s" (Doña-Reveco 2018). Largely due to its relative economic success as well as its perceived sense of social and political stability (Stefoni 2011), Chile quickly became a popular destination for relocation. In fact, “between 2010 and 2015, immigration to Chile grew at a faster rate than anywhere else in Latin America" (Doña-Reveco 2018). Since 2016, migrants began to arrive in unprecedented numbers due to economic and civil turmoil in Venezuela. In March 2018, the Department of Foreign Affairs and Migration was "attending an average of 4,000 people per day, and an estimated 1.1 million people [passed] through their offices" in 2018 (Gobierno de Chile 2018). This influx overwhelmed the government's 
ability to process visa requests and immigration became a popular topic of discussion amongst a polarized Chilean population. During the course of my research, the number of Venezuelans entering the country continued unabated. Consequently, migrants dealt with unparalleled wait times from government institutions when attempting to become regularized - a process which involves seeking a variety of documentation, including a visa, to allow migrants to live, work, and exist in a way that is deemed legal by the government. Additionally, severe unemployment and a growing disdain by Chileans about the increase of migrants targeted at particular racial and ethnic groups, defined many migrant's experiences in Santiago (Ciudad 2019, 2).

The laws that govern immigration to Chile are remnants of the Pinochet dictatorship. The Immigration Act of 1975 is currently in use. It was written in a restrictive era and only a few minor amendments have been made to it (Doña-Reveco 2018). In recent history, Chile has taken a generally welcoming attitude towards migrants under the assumption that the country "needed to repay a debt of solidarity to the rest of the world for having received the half million exiles of Pinochet's dictatorship" (Doña-Reveco and Levingson 2012). However, as migration increases and tensions rise, the antiquated immigration law is far from adequate, and "some argue the law is a relic of the Cold War and dictatorship, viewing immigrants as threats to national security. For others, it leaves too much open to interpretation and facilitates illegal immigration" (Doña-Reveco 2018). The Immigration Act of 1975 gave overwhelming power to the government as it "grants the federal executive (the military junta at the time of ratification) the authority to prohibit entry and deport any individual or group 'for reasons or interests of national security' with complete discretion," thus allotting the government with huge power and authority (Schmidt 2019, 13). Even still, recent rhetoric from the national government has emphasized a need to reduce the number of irregular immigrants in the country (Gobierno de Chile 2018). It has become clear to both proponents and detractors that the Immigration Act of 1975 needs an update (Gobierno de Chile 2018, Doña -Reveco 2018).

According to current Chilean law, a person can enter the country and receive a tourist visa that is valid for up to 90 days. During this time, individuals can apply for a number of visas which remain valid for a longer period of time, allowing them to stay in the country legally past the expiration of the tourist visa. Most commonly, migrants entering from a Mercosur trade nation (Argentina, Brazil, Paraguay, Uruguay, Venezuela, Bolivia, Columbia, Ecuador, Guyana, Peru and Suriname) apply for a temporary visa which is valid for one year, however, visas tied to job contracts and student visas also exist. Once a migrant has resided in the country for two years with temporary visas, they can apply for a definitive visa which is valid for five years, after which they can apply for citizenship (DEM n.d.). Under ideal circumstances, when entering the country, a migrant would apply for and receive a temporary visa before the 90-day period of their tourist visa expiry, thus residing in the country with a valid visa at all times. This ideal, however, is hardly ever reality, especially in the current era of increased migration (United Nations 2019) and is discussed in detail below. Consequently, migrants remain in the country without valid documentation (a status known as "irregular') until they receive their temporary visa. It is important to note that this irregularity is quite different from the illegality or lack of documentation that is discussed in the United States. Migrants who enter the country legally in Chile are at no risk of deportation and can regain a regular legal status by completing a bureaucratic process and paying fines. Migrants must pay a fine for every month spent in Chile without a valid visa. Tourist visas are administered by the border police and temporary visas are administered by the Department of Foreign Affairs and Immigration; this means that a migrant must work with both departments to acquire a temporary, working or student visa. There are a variety of documents, which vary depending on the migrant's country of origin, that migrants need in order to receive a visa. A new policy that went into effect on July 20th, 2019, required all Venezuelan migrants to Chile to receive a temporary, work, or student visa before 
entering the country, thus eliminating the option to enter as a tourist. This brief legal and policy framework outlines processes that migrants experience upon resettlement in Chile, yet it is important to understand that Chilean immigration laws are complex and changing. For example, Chile's New Migration Law was drafted, passed both chambers of Congress in August 2019 and implemented in April 2021 (Ministerio del Interior y Seguridad Pública 2019, 2021; Senado de Chile 2020).

\section{Methods}

This project was completed as part of the All College Thesis at the College of Saint Benedict and in collaboration with Dr. Megan Sheehan through a professor-student partnership grant. Additionally, we worked with a Chilean anthropology student, who conducted and transcribed interviews. I conducted qualitative research while living in Santiago, Chile between June and August of 2019. I gathered information through a series of semi-structured interviews with migrants and Chileans. I conducted 13 interviews and drew from a series of 57 interviews conducted by the aforementioned research team. The migrants were contacted through social media, posters, and word-of-mouth. They have been given pseudonyms here to protect their identities. The migrants varied in their origins, but nearly all interviewees had migrated from countries within South America, with the majority recently arrived from Venezuela. All interviews were recorded and transcribed, and translations are my own. Additionally, I drew data from participant observation conducted at an organization located in Santiago, Chile hereafter referred to as the Migration Foundation. At this organization, a team of social workers, lawyers, and volunteers helped migrants find employment and navigate the legal processes involved in becoming a working resident of Chile. My role at the Migration Foundation consisted of working one-on-one with migrants to learn about their employment history and current social situation to best help them secure employment and understand their financial needs. On average, I worked with 15 migrants a day for three days a week and completed field notes for every day spent at the Migration Foundation. Furthermore, while in
Santiago, I lived with a Chilean host family. Through them, I gained insights into Chilean political and social perspectives on migration.

Admittedly, this study was limited in its findings. Ideally, this ethnographic study would have taken place over the course of several years, as opposed to months. This would have led to a more holistic view of immigration in Chile and, perhaps, more confident and concrete findings. Furthermore, while proficient in the Spanish language, I feel I lacked the ability to understand more colloquial and nuanced forms of the language that would be crucial in fully understanding those whom I interviewed. Furthermore, stronger language skills would have created more meaningful relationships between me and the population I sought to understand. Despite these obstacles, I worked diligently to accurately represent the sentiments and views of immigrants and Chileans in Santiago.

\section{The State}

In the process of relocating to a new country, migrants develop a relationship with a second state. This relationship often reflects both a mixture of their old ideas of the state developed in their home countries and ideas formed through encounters with the state in the country of relocation. The state is "both an abstract, macro-level structure and a concrete, microlevel set of institutions," that creates governing and power establishments through bureaucratic structures (Auyero 2012, 6). It is this very distinction that correlates with the occurrence of positive and negative affects among Venezuelan migrants; the abstract, macro level state producing the former and the microlevel bureaucracies producing the latter. A large part of this macro-level structure is the significance that people attribute to it so that it becomes more than the sum of its parts: "the reification of this system [...] takes on 'an overt symbolic identity progressively divorced from practice as an illusory account of practice"' (Mitchell 2006, 169). The state comes to exist in the minds of people through the feelings produced in their everyday interactions with it. Akhil Gupta argues that "the most immediate context for encountering the state is provided by their relationships with government bureaucracies at the local 
level" (Gupta 1995, 378). In fact, most states are aware of this and work to foster better relationships through these methods: "they attempt to materialize this contract between citizens and institutions. They are made up of public 'things' such as offices, documents, technocratic procedures and infrastructures that seek to provide the foundation for social relationships with the state" (Bear and Mather $2015,19)$. Bureaucracies, as they function as an intermediary link between civilians and the state, are important in how the state is viewed. It is then curious that the Venezuelan migrants with whom I spoke, expressed such contrasting views of individual bureaucracies and the reified state.

Venezuelan migrants were generally grateful towards their new home country and anticipated that the reified state would be instrumental in providing them with a better life. In my interview with Lucia, the Venezuelan professor, she told me: "I believe that the government of Chile has helped a lot, it has supported a lot, and with the boom, the number of Venezuelans that came from 2015 to 2018 was very large, many people." She went on to say that she did not mind that the government had begun to filter the number of immigrants from Venezuela because the Chilean state needed to protect its own country first. Lucia, like many of the Venezuelan migrants I interviewed, saw their experiences with the Chilean state in contrast to the problems of the Venezuelan state. Even if the Chilean bureaucracies caused inconvenience, they were small in comparison with those of the Venezuelan state; consequently, they maintained a positive view of the Chilean state. In another interview, Eduardo, a middle-aged Venezuelan man, said "in reality, they do treat us very well here," right after explaining all the bureaucratic issues he had encountered, proving the migrant's ability to separate their own affective responses to micro and macro level structures. Most Venezuelan migrants shared this perspective, they were empathetic and felt warmth towards the state despite the daily grievances it caused them. In all, these contradictory affective responses are formative in a migrant's opinions of the state which is ultimately crucial to their experience of living a new country.

\section{Bureaucracy}

As individuals migrate and settle in new countries, they often experience bureaucratic processes of relocation. These processes in Chile, due to the increased rates of migration, became particularly intrusive in the lives of migrants during the months when my field research took place. Bureaucracy, and its impact on society, has long been a focus of social science research. In the field of sociology, Max Weber $(1921,89)$ described bureaucracy as "the means of transforming social action into rationally organized action." Bureaucratic structures are a way for the state to create order in a given population. The concept of bureaucracy has developed greatly from Weber's initial definition and now has connotations far beyond a management technique. Current work on bureaucracy recognizes the amorphous and hazy modes through which bureaucracies present themselves to a given society (Auyero 2012, Bear and Mather 2015, Gupta 1995). The processes, people, and ideas that are deemed "bureaucratic" are often blurred: "the elusiveness of the boundary between state and society, [is not] a problem of conceptual precision but a clue to the nature of the phenomena" (Mitchell 1999, 170). The less society knows about bureaucracies, the less power the former has over the latter. This power dynamic is not necessarily the product of intentional maliciousness on behalf of bureaucratic structures, but a result of attempts to govern large bodies of people, especially during rapidly changing times such as those present in Chile during the summer of 2019. As members of society deal "with state bureaucracies, they have to patiently comply with the seemingly arbitrary, ambiguous, and always changing state requirements" (Auyero 2012 , 9). Additionally, it is important to view the dual nature of bureaucracies. On one hand, they are abstract, ambiguous, large-scale structures. On the other hand, "bureaucracies and bureaucratic encounters are affective. They produce and are produced by emotion, selfinterest, social networks and much more" (Tuckett 2015, 114). They are dually abstract and intensely personal. As migrants encounter bureaucratic structures, they can 
experience a wide range of emotions, both positive and negative, which frame their time in Chile and shape their relation to the Chilean state.

One of the most consistent ways in which immigrants in Santiago experience bureaucracies is through the process of waiting. In order to become a legal citizen with a definitive visa who can work and live in Chile, migrants have to go through several procedures, most of which involve them filling out paperwork, sending it to a government office, either via physical mail or email, and then awaiting response. There is essentially nothing that a migrant can do to speed up this course of action and the wait can often leave migrants in limbo between legal statuses, complicating nearly all other aspects of their lives from employment to housing. Waiting, especially in circumstances when the awaited documents will provide ease of life, is a "temporal process in and through which political subordination is reproduced" (Auyero $2012,2)$. Waiting is generally an action ripe with status and autonomy; those who have power infrequently wait for anything. Contrarily, those with less power and who must wait, live in a state of uncertainty and lack authority. This waiting period is full of emotions both towards the waiting itself and the larger entities responsible for the waiting. The waiting itself produces negative emotions, however, the arrival of what is being waited for, often brings joy and relief, thus producing conflicting and complicated affective responses.

Migrants must wait for many things. In their new society, they have little power, autonomy, information, or cultural capital, and thus, they wait. It was part of my role at the Migration Foundation to help migrants navigate the required visa processes in Chile. It is important to note that the duration of these waits was unprecedentedly long and they continued to lengthen even in the short period in which I completed my field research. The entire process of getting a temporary visa had once taken roughly six weeks to complete from start to finish; however, I regularly had migrants tell me that they had to wait five or six months to have the initial meeting with Department of Foreign Affairs and Migration. In the time when migrants were waiting for this visa, after the expiration of their tourist visa, they would have to pay a fine for residing in the country without a legal visa. Camila, a Venezuelan woman in her sixties, stated that the Department of Foreign Affairs and Migration "is very slow, very slow. I imagine it is because of the current demand, they are not as automatic, I do not know. I know that there are many migrants at the moment and this could generate delay." She went on to say that her "documents were already at the Department of Foreign Affairs, but they take too much time, too much time and, sadly, you have to wait, you have to wait." Camila was clearly upset about the length of time her visa application was taking to process. The very process of attempting to become a regular citizen made her and many other migrants irregular while they waited for their visas to process. Migrants grumbled at this complication as it was a financial burden and existing outside of the law brought fear to their daily lives. However, because this process has become reified, migrants felt that there was no other option but to acquiesce. This aspect of bureaucracy was further complicated by the fact that most migrants also found themselves waiting for a job. Many migrants chose Santiago based on the city's economic opportunities, but the unemployment rate was around $7 \%$ even for Chileans who had connections and the appropriate cultural knowledge (INE 2019). Therefore, paying the fine for being irregular is often a great encumbrance on the migrants which adds additional worries to an already difficult situation. Migrants expressed strong negative emotions towards these bureaucratic structures, yet they endured them for the positive outcomes.

Additional bureaucratic entities that migrants encounter are the laws that govern them. It is an unfortunate reality that "migrants must grapple with ambiguous and arbitrary laws that shift across space and time" (Tuckett $2015,114)$. This theme was a reality during my field research between June and August of 2019 in Chile. As previously mentioned, the Department of Foreign Affairs and Migration made a change in policy that went into effect on July 20th, 2019, insisting that Venezuelans apply for temporary visas before entering Chile (Ministerio del Interior y Seguridad Pública 
2019). The changes in policy created confusion for the migrants. On the days leading up to July 20th, there was an increase of migrants seeking legal help from the lawyers at the Migration Foundation and asking questions regarding their immigration status. Their confusion and fear were palpable. Although I usually only helped with finding employment, several migrants asked me questions about immigration laws and where they could find more information. For example, one woman asked me several questions about her own regularization process and then a similar set of questions for her daughter. She took very detailed notes as she attempted to understand all the things that she needed to do. Earlier in fieldwork, this ambience of panic did not exist. The new policy also purposefully instilled ambiguity, allowing individual officers to make decisions about the length of the tourist visas. I began seeing migrants who had tourist visas that were only valid for a single day, again, forcing them to reside in the county irregularly. Because Venezuelans had to acquire visas prior to entry, their reliance upon their collapsed government for paperwork, like background checks, further limited their ability to legally enter Chile. Lucia, the Venezuelan professor, said she "intended to get a democratic (temporary) visa," but she explained that "it was very difficult. So, [she] had to travel as a tourist, and just two days after [she] arrived is when they changed the law where they allow the tourist visa." This policy was specifically targeted at Venezuelans, which would seemingly garner resentment, but migrant reactions were often quite different. Despite the frustrations of the bureaucratic processes themselves, migrants continued to speak of how grateful they were to be received by this larger, abstract entity that they referred to as the Chilean government or state. They accounted for any delays or changes to the augmentation of immigration to Chile. Eduardo, for example, noted that migrants were "coming in masses" and expressed that he was not surprised or angry that the visa process was taking so long, although he did admit that the wait was quite frustrating. While at times some migrants appeared frustrated with the changing laws, they were rarely angry with the state for making those changes because they understood that the influx of migrants was overwhelming the bureaucratic entities of the Chilean State.

While Venezuelan migrants expressed the contradictory views of the state and its bureaucracies, migrants who relocated from other countries had different affective responses. The interactions that these migrants have with the Chilean Border Police are often the first contact migrants have with their second state and these interactions can be incredibly affective. For example, one young man whom I helped at the Migration Foundation expressed this sentiment. He recounted that he had migrated from Peru and when he entered the country, the police at the border told him that he would need to return two days later to get a tourist visa. Yet when he returned two days later, the police refused to see him and so he was left without a visa. It was nearly a month after this occurred when I spoke to the young man, but he was still upset about the incident. He spoke in an exasperated tone and raised his voice appearing to try to catch the attention of the other migrants in the room so that they would share in his frustration. This man's view of the Chilean governing process was formed almost immediately as he entered the country and those frustrations towards the state lingered as we spoke nearly a month later. This young man's experience provides evidence that the trend of migrants holding negative affect towards bureaucracy and positive affect towards the state tends to be inapplicable beyond the demographic of Venezuelan migrants. Another woman, Julieta, shared her story of passing through the border from Peru to Chile and her resulting emotions towards the bureaucracies and state of Chile. She explained how she took a bus to cross the border. When she reached border control, the Chilean Border Police told everyone to disembark from the bus and to leave their belongings. Julieta emotionally recalled that she "did not know what was happening." She explained that the police then split the group into two, telling one group that they could continue their journey and the others that they could not. Julieta was in the group that was not allowed to pass. She said that the police did not even look at her passport or other documents, that they made distinctions among migrants based on 
appearances alone. Julieta concluded that the border police "treated us like shit." She was undoubtedly angry with the bureaucracies and the apparent injustice incurred at the border. These examples are some of the most extreme and these migrants hold a view of the state bureaucracies that is significantly worse and more skeptical than the other migrants with whom I spoke. However, their narratives are valuable in their ability to illuminate the process of producing negative affect. It is their fear, their frustration, and their confusion that constructs lasting views of the state, at both the macro and micro levels. These stories are reminders that migration is not an abstract idea, but a lived, emotional experience.

\section{Conclusions}

On October 18, just two months after I left Chile, the country erupted into either social disorder or a social awakening depending on perspective. Protests started in response to an increase in the cost of public transportation in Santiago -- the fourth within a year (Bunyan 2019). However, the demonstrations soon spread across the country. More than one million protestors took to the streets (BBC News Mundo 2019) in the week following the price increase and found themselves facing "police firing rubber bullets, tear gas and water cannons" (Bunyan 2019). The drastic response from the population was not only in response to public transportation costs but also "rising living costs, low wages and one of the worst rates of inequality in Latin America [...] Chile has the highest rate of income inequality among a group of 35 of the world's wealthiest nations" (Bunyan 2019). Rising tensions surrounding migration, with wide support from both perspectives, certainly contributed to the issue as well. Immigrants, many fleeing the crisis in Venezuela and in economic distress, contributed the drastic inequality and put a lot of pressure on a job market that was already suffering unemployment. In fact, on October 18th, the very day that the protests began, a Santiago newspaper published an article claiming that $51 \%$ of the Chilean population thought that immigration is bad for the country (Molina 2019). This came as somewhat unsurprising news as, a week before I left Chile, there had been an anti-immigrant protest in the center of Santiago. Several Chilean nationalists were marching through the streets wearing Chilean flags, yet this did not last long as an even larger opposing group soon arrived and things began getting violent. This growing antiimmigrant sentiment often made the claim that migrants were stealing their jobs and that they were changing the general atmosphere of the city. Contrarily, a study found that the foreignborn population of Chile is primarily economic (working) migrants and across all skill levels, migrants are working in positions that they are overqualified for, suggesting they are of value to the Chilean economy (Aldunate et al. 2019, 1). Essentially, Chileans are severely divided on their response to the surge in migration.

It is difficult to imagine that these social disruptions have made wait times even worse for migrants, many of whom have made great sacrifices to get to Chile. There is one last emotion that needs to be discussed with migration, one that supersedes all of the conflicting emotions that migrants feel towards the bureaucracies and the reified state. This emotion is heartbreak. The one emotion that I heard more commonly than any of those that I previously discussed is the destructive sorrow that one feels in leaving their home, family, friends, and culture behind. As Eduardo poetically put it, "I did not like to leave my land because it is difficult to put everything in one suitcase, all of your customs, your friends, your family, your style of life as well [...] to start from zero is not easy, to start from zero is not easy." In all this discussion of structures and policies, it is imperative to remember the distress many migrants have gone through, to recognize and understand their situation, and work to make their situation better. Emotions are a powerful tool in creating empathy and sparking progress. If the life of an immigrant in Chile is to improve, it must be done affectively. 


\section{Acknowledgements}

This paper would not have come to fruition if not for the patient guidance of my advisor, Megan Sheehan. Additionally, I would like to thank the migrants and Chileans who graciously offered their time and stories to an unfamiliar researcher. I will always be grateful for the ways you have impacted my life. 


\section{References}

Aldunate, Rosario, Gabriela Contreras, Claudia de la Huerta, and Matias Tapia. 2019. "Characterization of the Recent Immigration to Chile." Banco Central de Chile. https://ideas.repec.org/p/chb/ bcchwp/830.html.

Auyero, Javier. 2012. Patients of the State: The Politics of Waiting in Argentina. Durham: Duke University Press.

BBC News Mundo. 2019. “Protestas En Chile: La Histórica Marcha De Más De Un Millón De Personas Que Tomó Las Calles De Santiago." BBC. https://www.bbc.com/mundo/noticias-americalatina-50190029.

Bear, Laura, and Nayanika Mather. 2015. "Remaking the Public Good: A New Anthropology of Bureaucracy." The Cambridge Journal of Anthropology, 33(1): 18-34.

Bunyan, Rachael. 2019. "Chile Protests: What's Behind Social Unrest in Santiago?" TIME USA. LLC. https://time.com/5710268/chileprotests/.

Ciudad, Guillermo Pérez. 2019. "Migración en Chile: 5 Claves Para el Debate." Instituto de Estudios de la Sociedad. https:// www.ieschile.cl/wp-content/uploads/2019/03/Migracio\%CC\%81nen-ChileFinal.pdf.

DEM (Departamento de Extranjería y Migración). Nd. “Visa Temporaria." https://www.extranjeria.gob.cl/vivir-en-chile/visatemporaria/.

Doña-Reveco, Cristián. 2018. “Amid Record Numbers of Arrivals, Chile Turns Rightward on Immigration." Migration Policy Institute. https://www.migrationpolicy.org/article/amid-record-numbersarrivals-chile-turns-rightward-immigration.

Doña-Reveco, Cristián, and Amanda Levinson. 2012. “Chile: A Growing Destination Country in Search of a Coherent Approach to Migration." Migration Policy Institute. https:// www.migrationpolicy.org/article/chile-growing-destinationcountry-search-coherent-approach-migration\#: :text=Migration\% 20Information\%20Source-,Chile\%3A\%20A\%20Growing\% 20Destination\%20Country\%20in\%20Search,a\%20Coherent\% 20Approach\%20to\%20Migration\&text=Between $20750 \% 2$ C000\% 20and\%201\%20million,latest\%20governmental\%20estimates\% 20in\%202005. 
Gobierno de Chile. 2018. “New Immigration Law: promoting a modern immigration policy to meet Chile's needs." https:// www.gob.cl/en/news/new-immigration-law-promoting-modernimmigration-policy-meet-chiles-needs/.

Gupta, Akhil. 1995. “Blurred Boundaries: The Discourse of Corruption, the Culture of Politics, and the Imagined State." American Ethnologist 22: 375-402.

INE (Instituto Nacional Estadística). 2019. “INE publica resultados de la Encuesta Nacional de Empleo del trimestre agosto-octubre de 2019." https://www.ine.cl/prensa/2019/11/29/ine-publicaresultados-de-la-encuesta-nacional-de-empleo-del-trimestreagosto-octubre-de-2019.

Ministerio del Interior y Seguridad Pública. 2019. "Senado aprueba en general la Nueva Ley de Migraciones." https:// www.interior.gob.cl/noticias/2019/08/14/senado-aprueba-engeneral-la-nueva-ley-de-migraciones/.

Ministerio del Interior y Seguridad Pública. 2021. “Gobierno promulga la nueva Ley de Migraciones en Iquique." https:// www.interior.gob.cl/noticias/2021/04/11/gobierno-promulga-lanueva-ley-de-migraciones-en-iquique/.

Mitchell, Timothy. 2006. Society, Economy, and the State Effect. Malden: Blackwell.

Molina, Hernan Porras. 2019. “Estudio sobre la percepción de la inmigración: un 51\% considera que es negativa para Chile." https://www.entornointeligente.com/estudio-sobre-la-percepcinde-la-inmigracin-un-51-considera-que-es-negativa-para-chile/.

Schmidt, Patrick. 2019. “Playing by Pinochet's Rules: Legal and Constitutional Impediments to Progressive Immigration Reform in Chile." New York: Fordham University. https:// research.library.fordham.edu/cgi/viewcontent.cgi? article $=1038 \&$ context=international_senior.

Stefoni, Carolina. 2011. "Perfil Migratorio De Chile." Organización Internacional Para Las Migraciones. https://red-iam.org/sites/ default/files/2018-11/Perfil\%20Migratorio\%20Chile.pdf.

The United Nations Department on Economic and Social Affairs. 2019. "International Migrant Stock 2019." https://www.un.org/en/ development/desa/population/migration/publications/ migrationreport/docs/MigrationStock2019_TenKeyFindings.pdf. 
Tuckett, Anna. 2015. "Strategies of Navigation Migrants' Everyday Encounters with Italian Immigration Bureaucracy." The Cambridge Journal of Anthropology33(1): 113-128.

Weber, Max. 1921. "Bureaucracy." In Readings in Social Theory, 7th ed., edited by James Farganis, 89-100. New York: McGraw Hill, 2013.

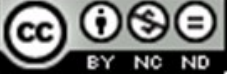

This work is licensed under a Creative Commons

Attribution-NonCommercialNoDerivatives

4.0 International License. 